\title{
Microstructure Evolution and Mechanical Properties of the 2195 Al-Li Alloy via Different Annealing and Ramp Heating-Up Treatments
}

\author{
Tian-Le Liu ${ }^{1}$, Jin-Feng Li ${ }^{1,2}$, Dan-Yang Liu ${ }^{1, * \mathbb{D}}$ and Yun-Long Ma ${ }^{3}$ \\ 1 School of Materials Science and Engineering, Central South University, Changsha 410083, China; \\ liu516037088@163.com (T.-L.L.); lijinfeng@csu.edu.cn (J.-F.L.) \\ 2 Key Laboratory of Nonferrous Materials Science and Engineering of Ministry of Education, \\ Central South University, Changsha 410083, China \\ 3 Beijing Institute of Astronautical Systems Engineering, Beijing 100076, China; mayunlong@csu.edu.cn \\ * Correspondence: liudanyang@csu.edu.cn; Tel.: +86-731-8887-9341
}

Received: 15 June 2020; Accepted: 6 July 2020; Published: 8 July 2020

\begin{abstract}
In this paper, the microstructure evolution of the 2195 Al-Li alloy under different isothermal annealing schedules and ramp heating-up heat treatments prior to solution heat treatment and the tensile properties of the aging alloy were investigated. The grain structure characteristics of the aging alloy could be influenced by the change of different heat treatment schedules prior to the solution heat treatment. Meanwhile, the mechanical properties of the aging alloy including strength, heterogeneity, and anisotropy were closely related to the grain structure characteristics. There were evident differences in the mechanical properties of aging samples, attributed to the mutual effect of grain structure evolution and texture change. Annealing at a lower temperature $\left(300-350{ }^{\circ} \mathrm{C}\right)$ resulted in the growth of the grain size and the aspect ratio as well as the decrease of the deformation texture components, related to the decline of the strength and the heterogeneity. While grains refined and the deformation texture components increased as the annealing temperature rose $\left(350-400{ }^{\circ} \mathrm{C}\right)$, the strength along the transverse direction decreased, and the heterogeneity increased. Fibrous and overall texture components significantly strengthened in the grain structure of aging samples treated with the low heating-up rate, resulting in a higher strength in the longitudinal direction.
\end{abstract}

Keywords: Al-Li alloy; microstructure evolution; grain structure; preannealing; tensile property

\section{Introduction}

Al-Li alloys possess a series of excellent properties such as low density, high elastic modulus, and high specific strength. Therefore, they have attracted intense attention from the aeronautic and aerospace industries. The $2195 \mathrm{Al}-\mathrm{Li}$ alloy is a typical third-generation Al-Li alloy, which has been successfully used in launch vehicles, fuel tanks, and aircraft [1]. The excellent mechanical properties of the $2195 \mathrm{Al}-\mathrm{Li}$ alloy are due to the addition of $\mathrm{Mg}$, Ag, and $\mathrm{Zn}$ elements and the appropriate $\mathrm{Cu} / \mathrm{Li}$ ratio, optimizing the precipitates [2]. However, some shortcomings, including high anisotropy and poor combination of strength and ductility of the third-generation Al-Li alloys, have hindered the further application of Al-Li alloys [3].

To optimize the mechanical properties and reduce the anisotropy used to meet the increasing need for designing advanced aerospace equipment, one of the most important methods is to improve the grain structure adaptability of Al-Li alloys [4]. Some studies show that severe plastic deformation [5], the addition of micro-alloying elements [6], and heat treatment [7] result in significant differences in the grain structures of Al-Li alloys. Ma et al. [8] studied the effect of cold rolling reduction on the grain structures of solutionized $1445 \mathrm{Al}-\mathrm{Li}$ alloy sheets. The fraction and size of the recrystallized grains in 
the solutionized sheets decreased with an increasing cold rolling reduction. Wang et al. [9] studied alloy sheets obtained by cold rolling possesses significantly elongated grains and relatively high stored energy, which constitute the driving force for recrystallization in the subsequent recrystallization annealing or solution treatment. Hence, recrystallization easily occurs in cold-rolled sheets during annealing or solution treatment, resulting in grain refinement and amelioration of the mechanical properties. The second-phase particles in alloys could also make a difference in the grain structure by affecting the recrystallization process. Suresh et al. [10] reported that the addition of Sc and $\mathrm{Zr}$ elements to the 2195 alloy resulted in grain refinement due to the presence of $\mathrm{Al}_{3}(\mathrm{Sc}, \mathrm{Zr})$ particles, which affected the stability of the sub-grain structure by exerting a drag force on the sub-grain boundaries, and further influenced recrystallization. Moreover, the recrystallization process of the alloys is also related to heat treatments after severe plastic deformation. Xiao et al. [11] designed electro-pulsing-assisted recrystallization annealing to rapidly complete the recrystallization process and lead to grain refinement. The impact of recrystallized grains on mechanical properties is bifacial: on the one hand, recrystallization can result in grain refinement, which can promote the strength and keep the ductility at a high degree, and on the other hand, it may weaken the crystallographic texture, which is well known for strengthening Al-Cu alloys.

Modification of the texture characteristics is also an essential aspect of the grain structure related to the mechanical properties of Al-Li alloys. Many works have been executed on the texture evolution of rolled and annealed Al-Li alloys. In terms of the rolling process, the grains are gradually rotated to $\beta$ fiber running from the Brass $\{110\}<112>$ to Copper $\{112\}<111>$ through the $S\{123\}<634>$ orientation, and then finally steadily located on $\beta$ fiber. Vasudevan et al. [12] conducted a similar study showing that Brass $\{110\}<112>$ usually formed in Al-Li alloys. After annealing or solution treatment, the crystallized texture components, including the textures near $\alpha$ fiber such as Goss $\{110\}<100>$ and Cube $\{100\}<100>$, grew sharply. Roy et al. [13] examined the evolution of microstructure and mechanical properties of the alloy under annealing treatment following severe plastic deformation. It was confirmed that annealing and cold-rolling have a significant influence on the texture of components. Wang et al. [14] investigated texture evolution with different intermediate annealing treatments of Al-Mg-Si-Cu alloys and found that low-temperature annealing is beneficial to form recrystallized texture components. Huo et al. [15] obtained steady hardness distribution and excellent texture composition of the $1060 \mathrm{Al}$ alloy by discussing isothermal and isothermal annealing.

In summary, extensive investigations have demonstrated that grain structure optimization is connected firmly with the microstructure evolution of recrystallization and texture. To date, although abundant works have focused on improving the grain structure adaptability of the Al-Cu alloy or $\mathrm{Al}-\mathrm{Mg}$ alloy $[16,17]$ through various micro-alloying elements and processes. However, few studies have been conducted on the optimization of the grain structure related to the mechanical properties of the $2195 \mathrm{Al}-\mathrm{Li}$ alloy via preliminary heat treatment prior to solution treatment. The current investigation aims to study the grain texture characteristic of the aging $2195 \mathrm{Al}-\mathrm{Li}$ alloy via different heat treatments prior to the solution treatment. The different grain texture characteristics was linked to the mechanical properties of the studied aging alloy. It offered a novel way to adjust the mechanical properties of the aging alloy by structuring optimize grain structure characteristics on the addition of the heat treatment prior to the solution heat treatment.

\section{Experimental}

The experimental $2195 \mathrm{Al}-\mathrm{Li}$ alloy plate with the chemical composition shown in Table 1 was supplied by Southwest Aluminum Co., Ltd. The original thickness of the sample was $20 \mathrm{~mm}$. The alloy plates were firstly subjected to cold rolling with a $75 \%$ reduction to $5 \mathrm{~mm}$. Different preliminary heat treatment schedules were designed to study the effect of the corresponding aging samples on the grain texture feature. The cold-rolled samples were then subjected to annealing treatments with different temperatures prior to the solution heat treatment. The isothermal annealing at temperature was a range of $300-400{ }^{\circ} \mathrm{C}$ for $2 \mathrm{~h}$. Besides, the cold-rolled samples were under ramp heating-up with different 
rates during the solution process, including a high heating-up rate (around $10^{\circ} \mathrm{C} / \mathrm{min}$ ), a medium heating-up rate (around $\left.5^{\circ} \mathrm{C} / \mathrm{min}\right)$, and low heating-up $\left(<2{ }^{\circ} \mathrm{C} / \mathrm{min}\right)$.

Table 1. The chemical composition of the studied 2195 Al-Cu-Li alloy (in wt. \%).

\begin{tabular}{ccccccccc}
\hline $\mathbf{C u}$ & $\mathbf{L i}$ & $\mathbf{M g}$ & $\mathbf{A g}$ & $\mathbf{M n}$ & $\mathbf{Z r}$ & $\mathbf{Z n}$ & $\mathbf{T i}$ & $\mathbf{A l}$ \\
\hline 4.12 & 1.02 & 0.44 & 0.28 & 0.25 & 0.12 & 0.25 & 0.10 & Bal. \\
\hline
\end{tabular}

After two kinds as mentioned above heat treatments, the sheets were solutionized at $505{ }^{\circ} \mathrm{C}$ for $50 \mathrm{~min}$, followed by quenching in cold water, and were then subjected to T8 temper-aging treatment $\left(150{ }^{\circ} \mathrm{C}\right.$ for $34 \mathrm{~h}$ after $4 \%$ pre-stretch deformation). The schematic of the processing route is shown in Figure 1. The microstructure evolution of the studied alloy during the different process procedures was detailed characterized to examine the influence of the preliminary heat treatment on the grain texture characteristics related to the mechanical properties of the aging alloy.

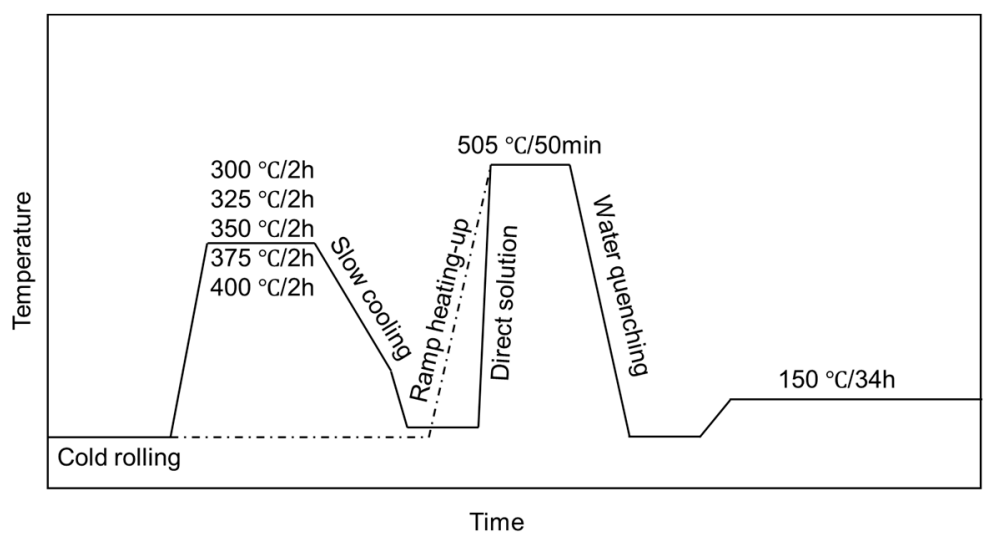

Figure 1. The route of entire process procedures of the Al-Cu-Li alloy in this experiment.

The tensile properties of the aged samples were characterized on an MTS 858 universal testing machine (MTS Industrial Systems CO.,LTD., Minneapolis, MN, USA) with a strain rate of $1.0 \times 10^{-3} \mathrm{~s}^{-1}$ at room temperature. Samples with a parallel section gauge of $45 \mathrm{~mm}$ in length and $12.5 \mathrm{~mm}$ in width were cut from the cold-rolled sheets along with the longitudinal and transverse directions, respectively. To ensure the data reliability, three parallel samples were tested for each condition.

The samples for metallographic characterization were cut from the longitudinal direction of the solutionized sheets, and then mechanically ground and polished. The samples were anodically coated at $0.1 \mathrm{~A}$ in a solution containing $1.1 \mathrm{~g} \mathrm{H}_{3} \mathrm{BO}_{3}, 95 \mathrm{~mL} \mathrm{H}_{2} \mathrm{O}$, and $3 \mathrm{~mL}$ hydrofluoric acid by a DC machine (direct current machine). The metallographic images were captured on the Leica DMI300 M optical microscope (Leica Microsystems Inc., Wetzlar, Germany). Scanning electron microscopy (SEM) was used to characterize the particles in the samples treated by different annealing treatments. The SEM images were taken from Quanta-200 environmental SEM (FEI CO., Hillsboro, OR, USA) under the backscattering modes.

Electron backscattered diffraction (EBSD) observations were performed on the Helios Nanolab 600i dual-beam electron microscope, and the scanning step size was $0.9 \mu \mathrm{m}$ at an accelerating voltage of $25 \mathrm{kV}$. HKL Channel 5 (Oxford Instruments, Oxford, UK, HKL Channel 5 version) was utilized to analyze the collected EBSD data. The detection rate of the raw EBSD data was $85 \%$ or more, and a standard noise reduction was applied to these raw data. Two kinds of boundaries were defined: low-angle boundaries (LABs) with a misorientation $(\theta)$ in the range of $2-15^{\circ}$, and high-angle boundaries (HABs) in the range as $\theta>15^{\circ}$.

Texture measurements taken by X-ray diffraction (XRD) were carried through a Brucker D8 Discovery $\mathrm{X}$-ray diffraction device at $40 \mathrm{kV}$ and $40 \mathrm{~mA}$ with $\mathrm{Cu} \mathrm{k}_{\alpha}$ radiation. The orientation distribution function 
(ODF) was calculated based on the incomplete pole figures in the three directions of $\{111\},\{200\}$, and $\{220\}$. The volume fraction of the texture components was determined quantitatively using the particle swarm optimization algorithm, and an angular deviation within $15^{\circ}$ was regarded as the same texture.

Samples for transmission electron microscopy (TEM) observation were prepared by mechanical grinding and twin-jet electropolishing in a solution containing 30\% nitric acid and $70 \%$ methanol (volume fraction) at $-25{ }^{\circ} \mathrm{C}-35{ }^{\circ} \mathrm{C}$ with a controlled current of $90 \mathrm{~mA}$. The observations were carried out through a Tecnai $\mathrm{G}_{2} 20$ transmission electron microscopy (FEI CO., Hillsboro, OR, USA) operating at $200 \mathrm{kV}$ through selected area electron diffraction (SAED) patterns and conventional dark-field (DF) images.

\section{Results}

\subsection{Metallographic Structure}

Figure 2 shows the metallographic pictures of the solutionized samples after isothermal annealing treatments at different temperatures. As presented in Figure 2, the directly solutionized samples exhibited the coexistence of equiaxed grains, elongated grains, and fibrous grains. The size of the equiaxed grains is small and the elongated grains have a lower aspect ratio.
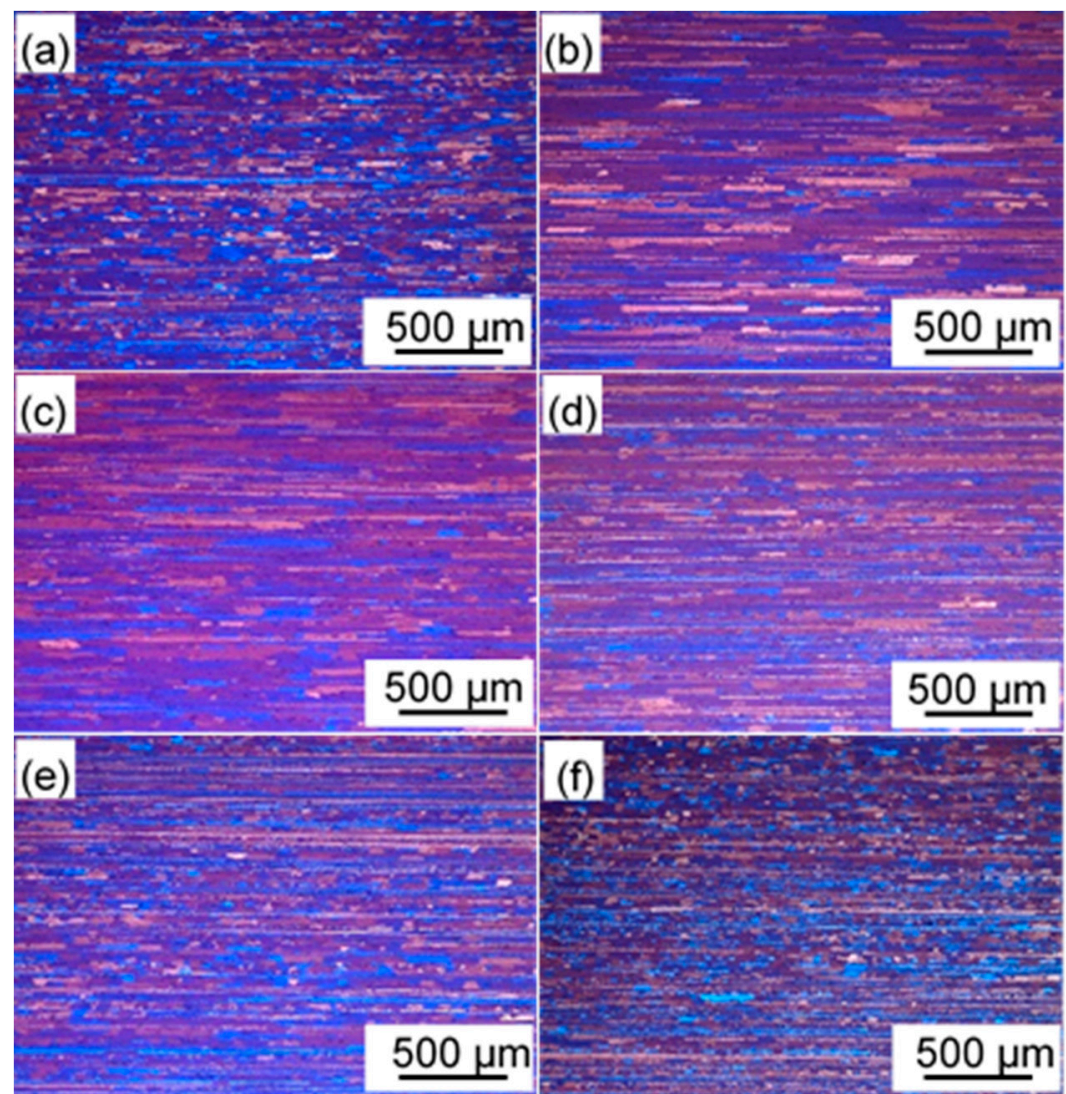

Figure 2. Longitudinal sectional metallographic pictures of solutionized samples after isothermal annealing at different temperature. (a) Direct solution; (b) $300{ }^{\circ} \mathrm{C}$; (c) $325^{\circ} \mathrm{C}$; (d) $350{ }^{\circ} \mathrm{C}$; (e) $375{ }^{\circ} \mathrm{C}$; and (f) $400{ }^{\circ} \mathrm{C}$.

For annealing treatments at a lower temperature $\left(300-350{ }^{\circ} \mathrm{C}\right)$ conducted on the cold-rolled sheets prior to the solution treatment, the equiaxed grains almost disappeared and the elongated grains coarsened, accompanied by an increase in the aspect ratio. After elevating the annealing temperature $\left(350-400{ }^{\circ} \mathrm{C}\right)$, the equiaxed grains reappeared again and the grains were refined compared to those 
annealed at a low temperature. Meanwhile, the content of fibrous grains were slightly raised. Instead of isothermal annealing treatments prior to the solution treatment, the cold-rolled sheets were subjected to ramp heating-up during the solution process (shown in Figure 3). The equiaxed grains disappeared and the morphology of the grains converted to fibrous grains in the samples treated by a low heating-up rate. The grains tend to coarsen and the fraction of fibrous grains reduced with a higher heating-up rate.
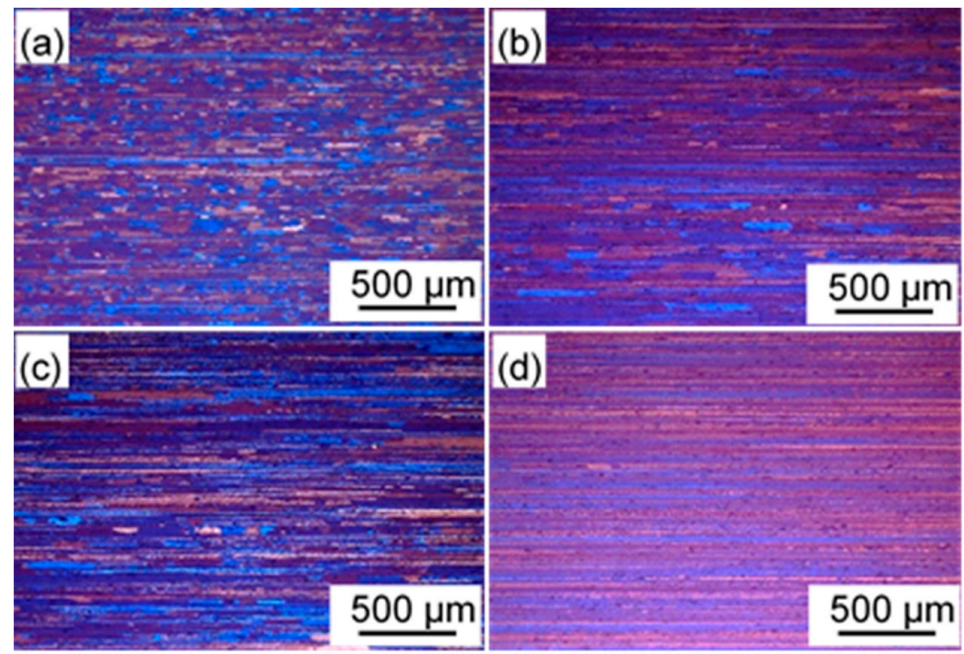

Figure 3. Longitudinal sectional metallographic pictures of solutionized samples after ramp heating-up treatments. (a) Direct solution; (b) $\sim 10{ }^{\circ} \mathrm{C} / \mathrm{min}$; (c) $\sim 5^{\circ} \mathrm{C} / \mathrm{min}$; and (d) $<2{ }^{\circ} \mathrm{C} / \mathrm{min}$.

\subsection{Evolution of the Texture Structure}

The ODF images of the annealing state samples with different annealing treatments and cold-rolled samples are shown in Figure 4. Brass $\{110\}<112>, S\{123\}<634>$, and Copper $\{112\}<111>$, namely $\beta$ fiber texture components shown in Figure 4a, formed after cold rolling. Meanwhile, Goss $\{110\}<100>$ and Cube $\{100\}<100>$ are also observed. The corresponding ODF images of the cold-rolled samples subjected to an isothermal annealing treatment at different temperatures are shown in Figure $4 b, c$. It is seen that the deformation texture components, including Brass $\{110\}<112>, S\{123\}<634>$, and Copper $\{112\}<111>$, weakened after the annealing treatment, while the recrystallization texture components, including Cube $\{100\}<100>$ and Goss $\{110\}<100>$, became stronger at the same time. The volume fraction of the textures was calculated through the particle swarm optimization algorithm, and the results are presented in Table 2. The overall volume fraction of the deformation texture declined after the annealing treatments $(42.23-38.35 \%)$. A lot of Copper $\{112\}<111>$ was found in the cold-rolled samples $(9.13 \%$ volume fraction, the same below), which disappeared after the annealing treatment. The total volume fraction of Brass $\{110\}<112>$ and $S\{123\}<634>$ increased after annealing at $300{ }^{\circ} \mathrm{C}$, and then decreased at $400{ }^{\circ} \mathrm{C}$. After annealing at $400^{\circ} \mathrm{C}$, R-Cube $\{100\}<110>$ texture was observed in the alloy. Furthermore, the volume fraction of Cube $\{100\}<100>$ rose as the annealing temperature elevated, while the volume fraction of Goss $\{110\}<100>$ remained stable during the annealing process. The volume fraction of the recrystallization textures peaked in the samples annealed at $400{ }^{\circ} \mathrm{C}(18.62 \%)$, which included a certain amount of R-Cube $\{100\}<110>(7.53 \%)$.

Table 2. Textures volume fraction of $2195 \mathrm{Al}-\mathrm{Li}$ alloy sheets after isothermal annealing at different temperatures $(\%)$.

\begin{tabular}{ccccccccc}
\hline $\begin{array}{c}\text { Heat Treatment } \\
\text { Schedule }\end{array}$ & Brass & Copper & S & Goss & Cube & R-Cube & R-Goss & $\begin{array}{c}\text { Other } \\
\text { Texture }\end{array}$ \\
\hline cold-rolled & 16.61 & 9.13 & 16.49 & 2.97 & 5.22 & 0 & 0.52 & 7.77 \\
$300^{\circ} \mathrm{C}$ & 19.03 & 0 & 21.56 & 3.46 & 5.94 & 0 & 1.1 & 9.19 \\
$400{ }^{\circ} \mathrm{C}$ & 17.45 & 0 & 20.9 & 2.91 & 8.18 & 7.53 & 0 & 4.84 \\
\hline
\end{tabular}



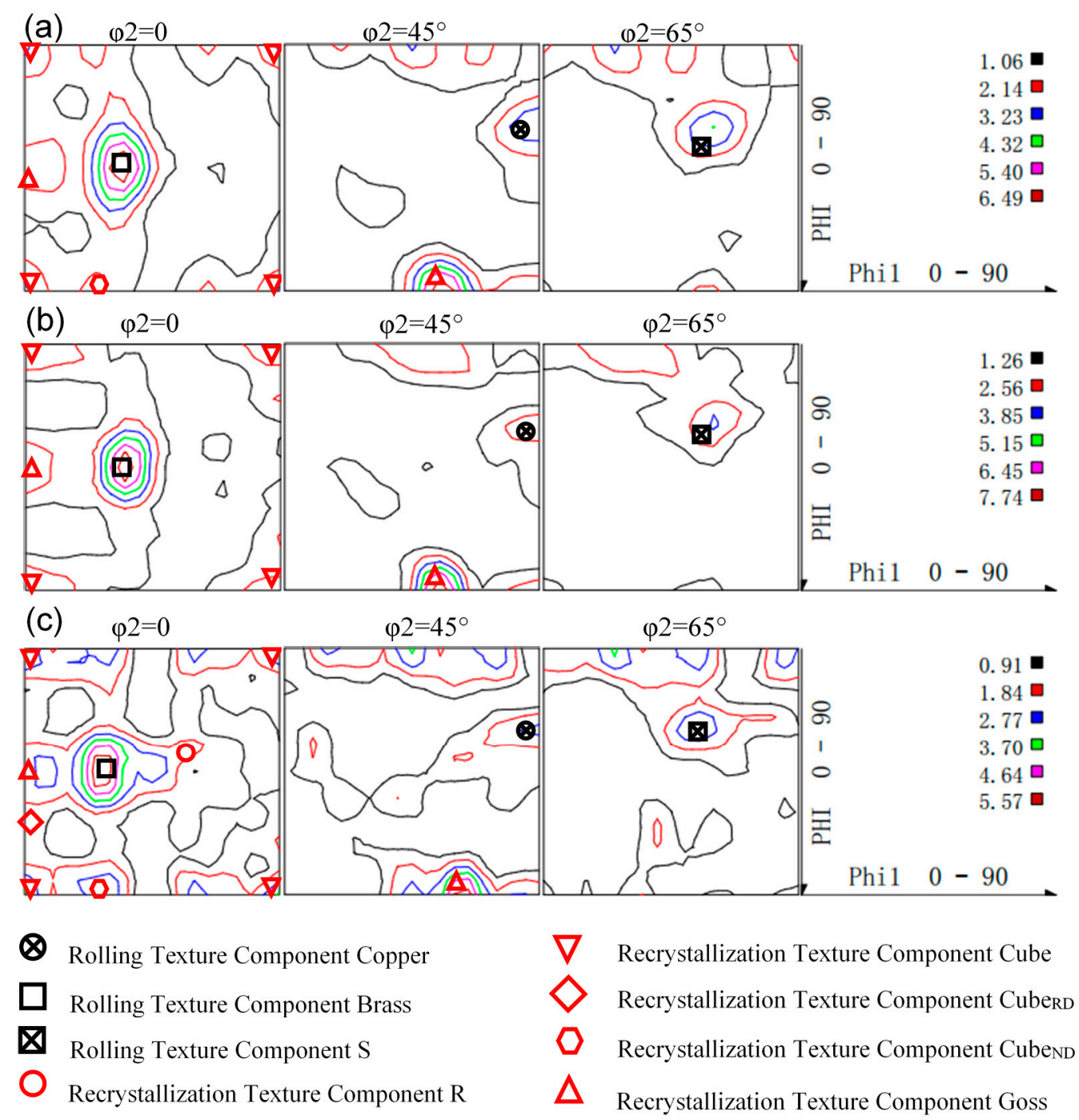

Figure 4. Orientation distribution function (ODF) images of $2195 \mathrm{Al}-\mathrm{Li}$ alloy sheets after isothermal annealing at different temperatures. (a) Cold-rolled; (b) $300^{\circ} \mathrm{C}$; and (c) $400{ }^{\circ} \mathrm{C}$.

Figure 5 shows the ODF images of the solutionized samples after different annealing treatments, low heating-up rate solution, and direct solution treatment. Table 3 presents the corresponding texture volume fractions of the solutionized samples under a different above-mentioned preliminary treatment. Compared to the cold-rolled or isothermal annealed samples shown in Table 2, the rolling texture components of the solutionized alloys became weaker and the total volume fraction of the textures also declined. However, the texture of the sheets treated with a low heating-up rate was not affected. In the solutionized samples after different annealing temperatures and a direct solution, Copper $\{112\}<111>$ was not observed. In addition, the volume fraction of Brass $\{110\}<112>$ decreased and Goss $\{110\}<100>$ slightly increased. Compared to the direct solution with different preliminary annealing schedules, the texture fraction of Goss remained stable (about 5.5\%).

Compared to the directly solutionized samples, in the samples annealed at $300^{\circ} \mathrm{C}, \mathrm{S}\{123\}<634>$ was not observed. Cube $\{100\}<100>(10.51 \%)$ and Goss $\{110\}<100>(5.54 \%)$ became the major texture components. For the samples annealed at $400{ }^{\circ} \mathrm{C}$, the fraction of Brass $\{110\}<112>$ and $\mathrm{S}\{123\}<634>$ increased to $22.66 \%$; the recrystallization texture components, including Goss $\{110\}<100>$ and Cube $\{100\}<100>$, decreased $(8.17 \%)$. Besides, in contrast to the samples treated by isothermal annealing prior to solution treatment, the evolution of texture with a low heating-up rate during the solution process was different. The total volume fraction of the texture components of the low heating-up rate solutionized 
sample increased substantially, especially the deformation texture (Brass $\{110\}<112>, S\{123\}<634>$, and Copper $\{112\}<111>$ : $28.51 \%, 15.47 \%$, and $18.43 \%$, respectively).
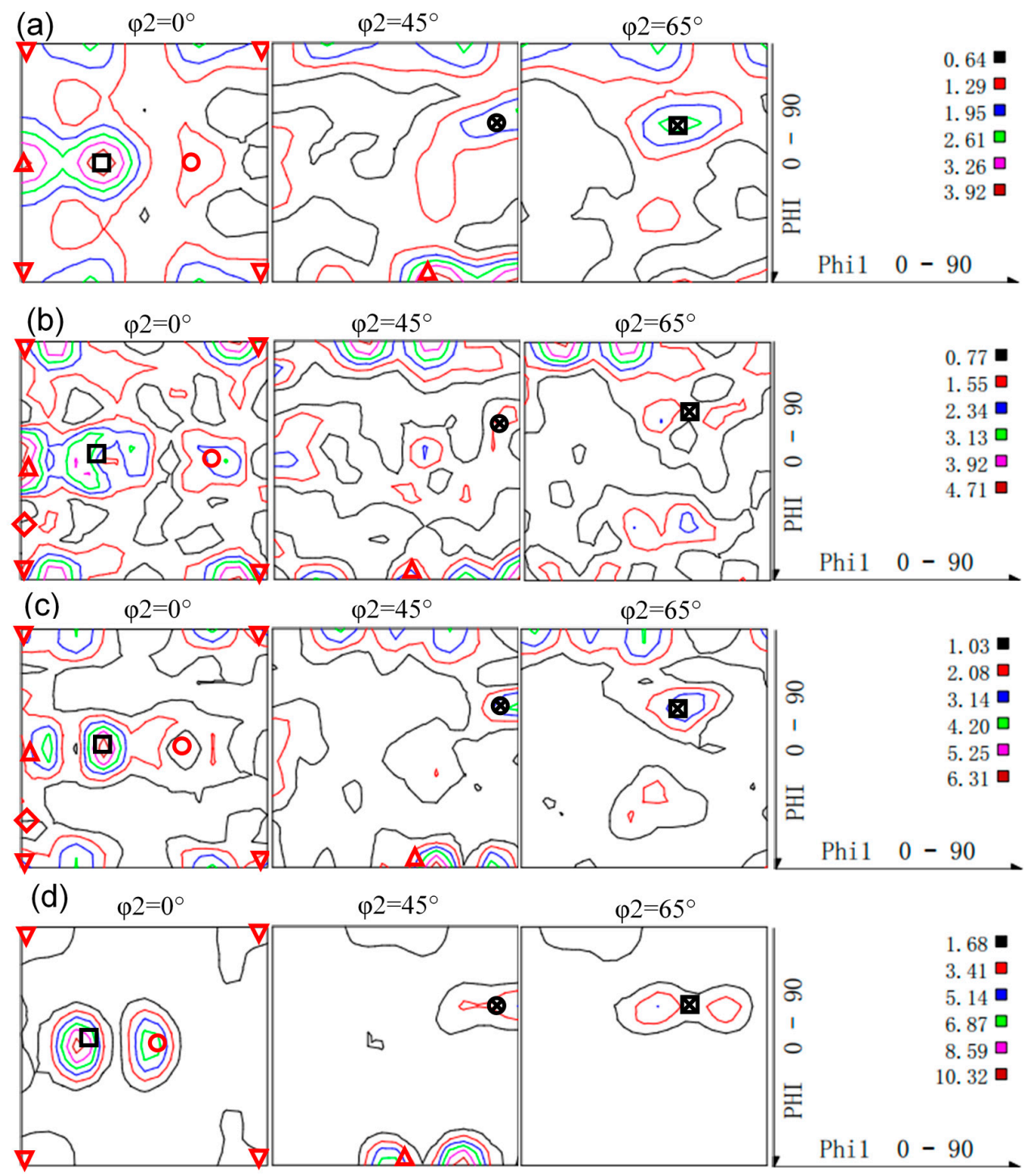
$\otimes$ Rolling Texture Component Copper
$\nabla$ Recrystallization Texture Component Cube
$\square$ Rolling Texture Component Brass
$\checkmark$ Recrystallization Texture Component Cube
区 Rolling Texture Component S
0 Recrystallization Texture Component Cube
Recrystallization Texture Component $\mathrm{R}$
$\triangle$ Recrystallization Texture Component Goss

Figure 5. ODF images of solutionized samples after different annealing treatments. (a) Direct solution; (b) $300{ }^{\circ} \mathrm{C}$; (c) $400{ }^{\circ} \mathrm{C}$; and (d) low heating-up rate.

Table 3. Textures volume fraction of solutionized samples after different annealing treatments (\%).

\begin{tabular}{ccccccc}
\hline $\begin{array}{c}\text { Heat Treatment } \\
\text { Schedule }\end{array}$ & Brass & Copper & S & Goss & Cube & $\begin{array}{c}\text { Other } \\
\text { Texture }\end{array}$ \\
\hline Direct solution & 10.81 & 0 & 13.21 & 5.36 & 0 & 7.05 \\
$300^{\circ} \mathrm{C}$ & 12.15 & 0 & 0 & 5.54 & 10.51 & 13.87 \\
$400^{\circ} \mathrm{C}$ & 8.05 & 0 & 14.61 & 5.49 & 2.68 & 24.29 \\
Low heating-up rate & 28.51 & 15.47 & 18.43 & 4.95 & 7.16 & 0 \\
\hline
\end{tabular}




\subsection{Microstructure Characteristics of the Grains}

To further investigate the microstructure of the grains, the EBSD outcomes of the solutionized samples after annealing treatments at different temperatures are presented in Figure 6. The LABs and the HABs are marked by white lines and black lines in the inverse pole figure (IPF) maps, respectively. The observation results from the IPF maps are in line with that of the metallographic pictures. As shown in Figure 6a,e,i, the grain size of the solutionized samples after the annealing treatment at $300{ }^{\circ} \mathrm{C}$ increased. In comparison, it was refined in the solutionized samples after the annealing treatment at $400{ }^{\circ} \mathrm{C}$ compared to the directly solutionized samples.
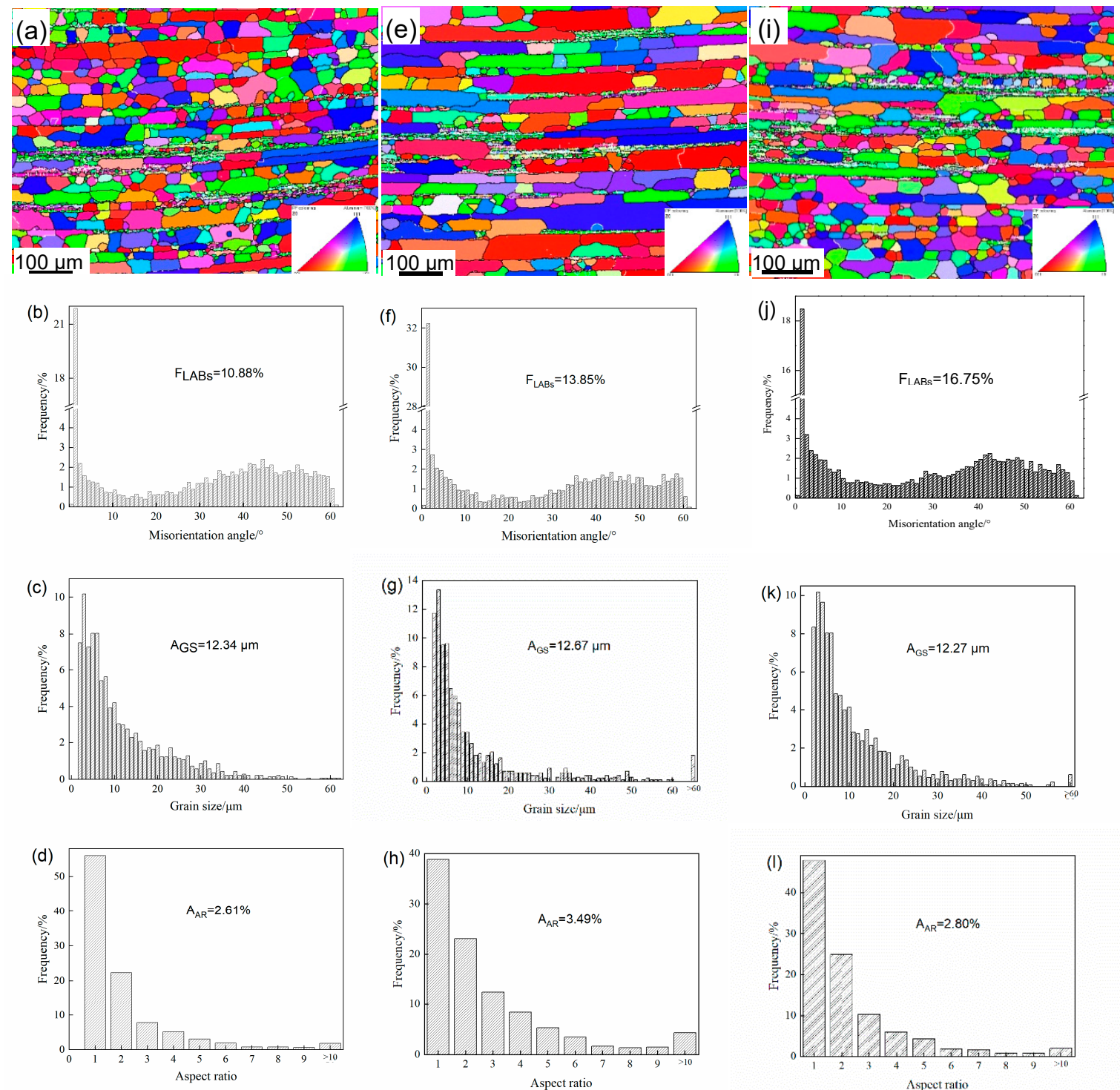

Figure 6. Electron backscattered diffraction (EBSD) images of solutionized 2195 Al-Li alloy sheets after annealing at $300{ }^{\circ} \mathrm{C}$ prior to solution. (a) Inverse pole figure (IPF) maps; (b) misorientation angle distribution; (c) grain size distribution; (d) grain aspect ratio distribution; and the solutionized $2195 \mathrm{Al}-\mathrm{Li}$ alloy sheets after annealing at $300^{\circ} \mathrm{C}$ prior to solution. (e) IPF maps; (f) misorientation angle distribution; (g) grain size distribution; (h) grain aspect ratio distribution; and the solutionized $2195 \mathrm{Al}-\mathrm{Li}$ alloy sheets after annealing at $400{ }^{\circ} \mathrm{C}$ prior to solution. (i) IPF maps; (j) misorientation angle distribution; (k) grain size distribution; and (1) grain aspect ratio distribution.

The statistical data of the grain sizes (in Figure $6 \mathrm{c}, \mathrm{g}, \mathrm{k}$ ) also demonstrate this conclusion from another perspective. The average grain size of the directly solutionized samples was $12.34 \mu \mathrm{m}$, and that 
of the samples annealed at $300^{\circ} \mathrm{C}$ and $400{ }^{\circ} \mathrm{C}$ as $12.67 \mu \mathrm{m}$ and $12.27 \mu \mathrm{m}$, respectively. Isothermal annealing before the solution treatment also had a significant influence on the grain aspect ratio. The difference in the grain aspect ratio between samples annealed at $400{ }^{\circ} \mathrm{C}$ and those directly solutionized was little (2.61 and 2.80). However, the grain aspect ratio of the samples annealed at $300{ }^{\circ} \mathrm{C}$ increased dramatically and achieved 3.49. As shown in Figure $6 \mathrm{~b}, \mathrm{f}, \mathrm{j}$, the directly solutionized samples obtained the lowest fraction of LABs (10.88\%). The samples were subjected to annealing prior to solution treatment, and the higher the annealing temperature, the higher the fraction of the LABs after solution treatment. The LABs fraction of the samples annealed at $400{ }^{\circ} \mathrm{C}$ had the highest- $16.75 \%$.

The recrystallization fraction of the $2195 \mathrm{Al}-\mathrm{Li}$ alloy sheets after the annealing at different temperatures was also studied. Figure 7 shows the recrystallization grains, the sub-structure, and the deformed structure of the solutionized samples after annealing treatments at different temperatures, and the specific data are shown in Table 4. The grain structures of the indirectly solutionized sheets are composed of recrystallized grains, a sub-structure, and a deformed structure. After annealing at $300{ }^{\circ} \mathrm{C}$ and the subsequent solution treatment, the sub-structure and deformed structure become more than that of the directly solutionized samples. However, the sub-structure decreased, and the recrystallized grains and deformed structure increased after annealing at $400{ }^{\circ} \mathrm{C}$ and followed by the solution treatment compared to the directly solutionized samples.
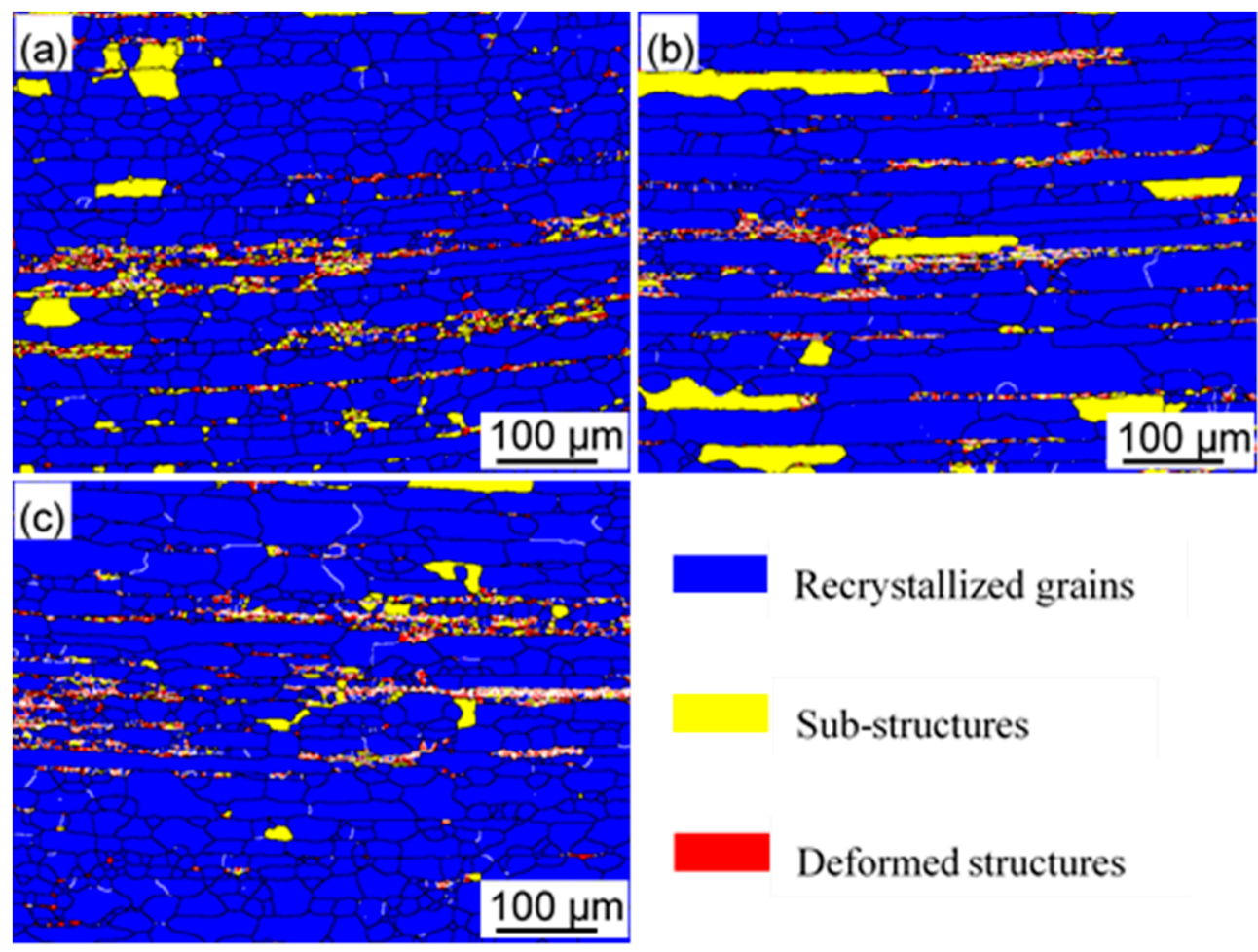

\section{Sub-structures}

\section{Deformed structures}

Figure 7. EBSD images showing the structure distribution of the solutionized samples after annealing at different temperature. (a) Direct solution; (b) $300{ }^{\circ} \mathrm{C}$; and (c) $400{ }^{\circ} \mathrm{C}$.

Table 4. The recrystallization fraction of the solutionized samples after annealing treatments at different temperatures $(\%)$.

\begin{tabular}{cccc}
\hline $\begin{array}{c}\text { Heat Treatment } \\
\text { Schedule }\end{array}$ & $\begin{array}{c}\text { Recrystallized } \\
\text { Grains }\end{array}$ & Sub-Structures & $\begin{array}{c}\text { Deformed } \\
\text { Structures }\end{array}$ \\
\hline Direct solution & 88.91 & 6.13 & 4.96 \\
$300^{\circ} \mathrm{C}$ & 85.92 & 8.70 & 5.38 \\
$400{ }^{\circ} \mathrm{C}$ & 91.00 & 3.02 & 5.98 \\
\hline
\end{tabular}




\subsection{Mechanical Properties}

After the solution treatment at $505{ }^{\circ} \mathrm{C}$ followed by $150{ }^{\circ} \mathrm{C}$ T8 aging, the cold-rolled $2195 \mathrm{Al}-\mathrm{Li}$ alloy under different annealing treatments exhibited different tensile properties. Figure 8 shows the tensile curves of the aged $2195 \mathrm{Al}-\mathrm{Li}$ alloy with different annealing treatments, along the longitudinal and transverse directions.
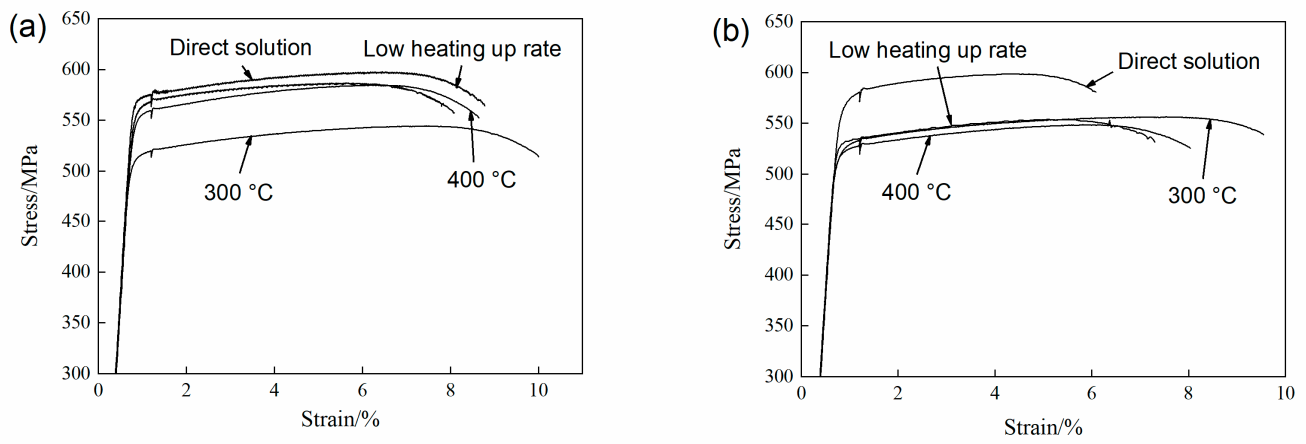

Figure 8. Tensile curves of the aged $2195 \mathrm{Al}-\mathrm{Li}$ alloy sheets with different annealing treatment after $\mathrm{T} 8$ aging following solution at $505{ }^{\circ} \mathrm{C}(\mathbf{a})$ longitudinal direction and (b) transverse direction.

Table 5 shows the corresponding tensile property values. The directly solutionized samples obtained the superior strength properties, both along with the longitudinal and transverse directions (587 MPa and $599 \mathrm{MPa}$ of tensile strength, respectively). After isothermal annealing treatment at $300{ }^{\circ} \mathrm{C}$, the strength of the alloy declined significantly. Elevating the annealing temperature to $400{ }^{\circ} \mathrm{C}$, the yield strength and the tensile strength along the longitudinal direction surged from $513 \mathrm{MPa}$ and $545 \mathrm{MPa}$ to $553 \mathrm{MPa}$ and $585 \mathrm{MPa}$, respectively. However, the strength along the transverse direction changed little, which means that the anisotropy of the alloy was more severe. After treatment with a low heating-up rate during the solution process, the tensile strength along the longitudinal direction increased slightly from 587 to $598 \mathrm{MPa}$. However, the tensile strength along the transverse direction decreased dramatically from 599 to $554 \mathrm{MPa}$.

Table 5. Tensile property values of $2195 \mathrm{Al}-\mathrm{Li}$ alloy sheets with different annealing treatment after T8 aging following the solution heat treatment.

\begin{tabular}{|c|c|c|c|c|c|c|c|}
\hline $\begin{array}{l}\text { Heat Treatment } \\
\text { Schedule }\end{array}$ & Direction & $\begin{array}{c}\text { Tensile } \\
\text { Strength/MPa }\end{array}$ & $\begin{array}{l}\text { Standard } \\
\text { Deviation }\end{array}$ & $\begin{array}{l}\text { IPA of Tensile } \\
\text { Strength/\% }\end{array}$ & $\begin{array}{c}\text { Yield } \\
\text { Strength/MPa }\end{array}$ & $\begin{array}{l}\text { Standard } \\
\text { Deviation }\end{array}$ & $\begin{array}{c}\text { IPA of Yield } \\
\text { Strength/\% }\end{array}$ \\
\hline \multirow{2}{*}{$\begin{array}{l}\text { Without } \\
\text { annealing }\end{array}$} & Longitudinal & 587 & 0.83 & \multirow{2}{*}{2.04} & 562 & 0.93 & \multirow{2}{*}{1.60} \\
\hline & Transverse & 599 & 1.80 & & 571 & 1.41 & \\
\hline \multirow{2}{*}{$300^{\circ} \mathrm{C}$} & Longitudinal & 545 & 5.43 & \multirow{2}{*}{2.02} & 513 & 3.53 & \multirow{2}{*}{2.14} \\
\hline & Transverse & 556 & 6.44 & & 524 & 4.77 & \\
\hline \multirow{2}{*}{$400^{\circ} \mathrm{C}$} & Longitudinal & 585 & 0.28 & \multirow{2}{*}{6.56} & 553 & 0.63 & \multirow{2}{*}{5.94} \\
\hline & Transverse & 549 & 7.16 & & 522 & 9.13 & \\
\hline \multirow{2}{*}{$\begin{array}{l}\text { low heating-up } \\
\text { rate }\end{array}$} & Longitudinal & 598 & 3.42 & \multirow{2}{*}{7.94} & 566 & 5.56 & \multirow{2}{*}{6.59} \\
\hline & Transverse & 554 & 4.72 & & 531 & 2.79 & \\
\hline
\end{tabular}

The heterogeneity parameter (IPA, H) was calculated according to the following equation:

$$
H=\left|I_{0}-I_{90}\right| / I_{\min } \cdot 100 \%
$$

where $I_{0}$ refers to the strength value along the longitudinal direction; $I_{90}$ refers to the strength value along the transverse direction, and $I_{\min }$ is the minimum value between $I_{0}$ and $I_{90}$. The IPA of the T8-aged $2195 \mathrm{Al}-\mathrm{Li}$ alloy sheets with different annealing treatments is also presented in Table 5, which shows less heterogeneity for the samples directly solutionized and annealed (at $300{ }^{\circ} \mathrm{C}$ ). 


\subsection{Microstructure Characteristics}

The back-scattering electronic scanning observation was conducted to examine the second phase particle characteristics of the 2195 Al-Li alloy at different annealing conditions (in Figure 9). As shown in Figure 10a, two types of particles classified by size were presented. It included small-size particles $(1 \mu \mathrm{m})$ and large size particles $(>5 \mu \mathrm{m})$. The evolution of the second phase particles in 2195 Al-Li alloy is mainly reflected in the mutual transformation of these two types of particles. After being annealed at $300{ }^{\circ} \mathrm{C}$, there was a big reduction of the number of small-size particles due to the dissolution or growth, which resulted in the decline of the density of particles and the Zener pinning pressure weakened. As a consequence, the size of grains grown and the average aspect ratio elevated as well. However, for those annealed at $400{ }^{\circ} \mathrm{C}$, the large-size particles started discomposing, leading to a number of the large particles to decrease and the amount and density of small-size particles increased simultaneously. Hence, the grains refined, and the average aspect ratio decreased at $400{ }^{\circ} \mathrm{C}$

Figure 10 shows the TEM images of aged samples, including the dark field image and SAED patterns with different annealing treatment temperatures at $300{ }^{\circ} \mathrm{C}$ and $400{ }^{\circ} \mathrm{C}$. As seen from Figure 11 , the thin needle-like precipitates were considered as the $\mathrm{T}_{1}$ phase, which owned the habit plane located at $\{111\}_{\alpha}$ corresponding to the streaks at $1 / 3\{220\}$ and $2 / 3\{220\}$ from the 112$]_{\mathrm{Al}}$ zone axis (Figure 10b,d). The $\mathrm{T}_{1}$ phase was the primary precipitates in the studied aging 2195 alloy. It could be found that the size and quantity of the $\mathrm{T}_{1}$ phase in T8-aged samples annealed at $300{ }^{\circ} \mathrm{C}$ and $400{ }^{\circ} \mathrm{C}$ were almost the same (Figure 10a,c). Thus, the strength difference of the aging alloys among the different preliminary heat treatment schedules was attributed to the grain texture characteristics.
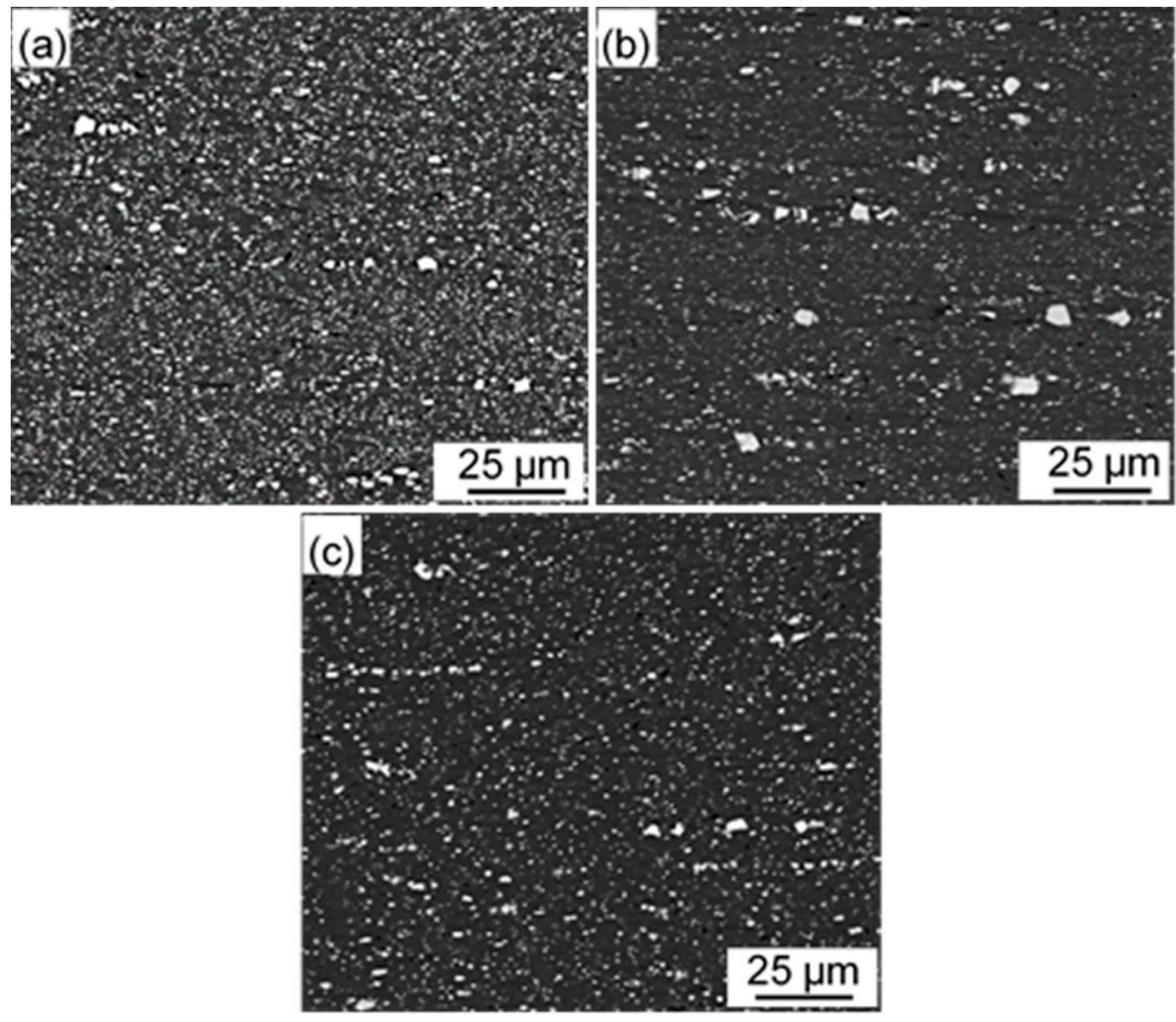

Figure 9. SEM images of $2195 \mathrm{Al}-\mathrm{Li}$ alloy sheets after annealing at different temperature. (a) Cold-rolled; (b) $300{ }^{\circ} \mathrm{C}$; and (c) $400{ }^{\circ} \mathrm{C}$. 

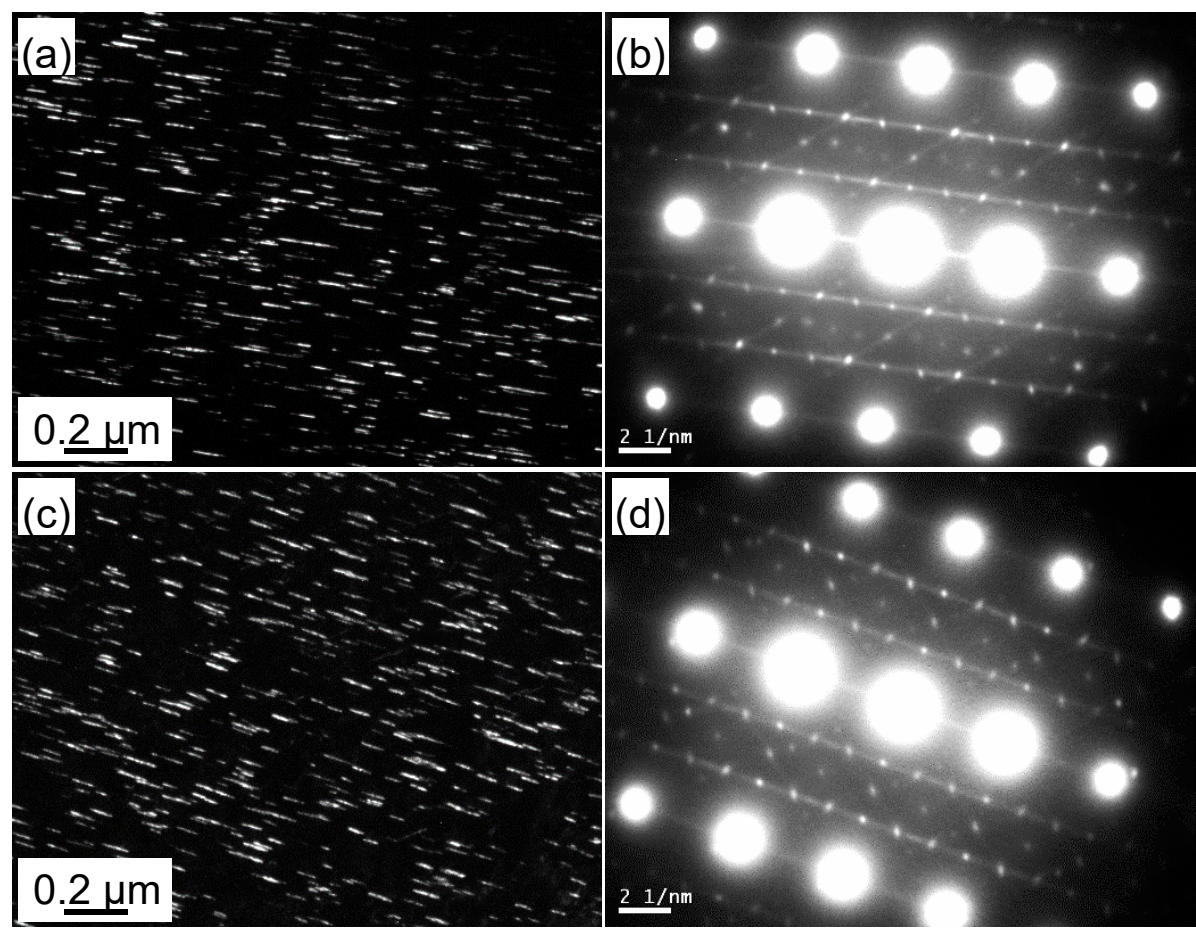

Figure 10. TEM observation showing the dark figure (DF) and the SAED patterns (which subjected the reciprocal changes by the operation of counter clockwise rotation with $90^{\circ}$ to easily correspond the consistent orientation of the studied precipitate located on $\{111\}_{\mathrm{Al}}$ ) of T8-aged samples after annealing at different temperatures: (a,b) $300{ }^{\circ} \mathrm{C}$ and $(\mathbf{c}, \mathbf{d}) 400{ }^{\circ} \mathrm{C}$.

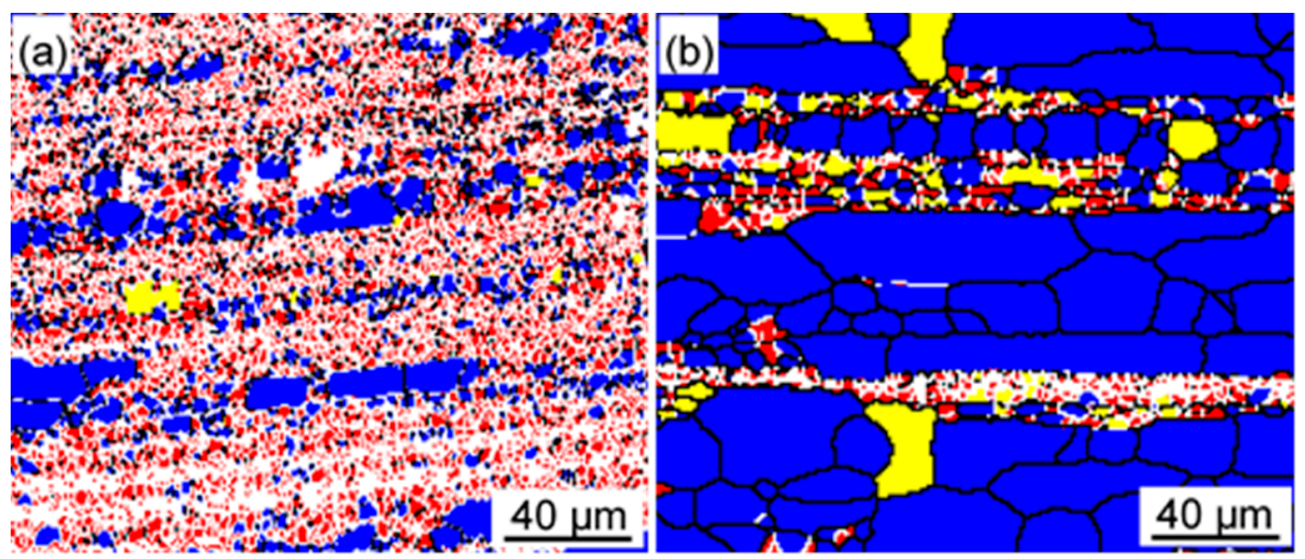

Figure 11. The magnified local structure distribution of $2195 \mathrm{Al}-\mathrm{Li}$ alloy sheets before and after solution with the annealing treatment at $400{ }^{\circ} \mathrm{C}$. (a) Before solution and (b) after solution.

\section{Discussion}

\subsection{The Evolution of the Grain Structures}

It is well known that recrystallization structure inevitably generates during the mechanical thermal processing of the Al-Cu-Li alloy, with the primary driving force of the stored energy caused by plastic deformation [18]. Moreover, the size of recrystallized grains results from the number of nucleation sites. The classical Johnson-Mehl model can express the connection between the nucleation sites and the size of recrystallized grains.

$$
d=C \cdot(G / N)^{1 / 4}
$$


where $d$ refers to the size of the recrystallized grains; $G$ refers to the growth rate of the recrystallized grains; $N$ refers to the nucleation rate; and $C$ is a constant. Recrystallization tends to nucleate at defective interfaces heterogeneously. For example, dislocations move and rearrange during the annealing treatment, accompanied by the vanishing of many vacancies due to the thermal activation. Therefore, after the annealing treatment at $300^{\circ} \mathrm{C}$, the stored energy of the cold-rolled sheets is mostly released, leading to a reduction of the recrystallization fraction and the coarsening of the grain size in subsequent solution treatment. However, after annealing at $400{ }^{\circ} \mathrm{C}$ and the subsequent solution treatment, the recrystallized grains became refined, and the fraction of recrystallization increased. This is owing to the fact that the sub-grains and high angle boundaries formed during the annealing treatment can serve as new nucleation sites for recrystallization during the following solution process. After annealing treatment at $400{ }^{\circ} \mathrm{C}$ (Figure 11), some recrystallization grains and sub-structures were formed in the alloy, which served as recrystallization nucleation sites and resulted in nucleation with sub-structure coalescence and growth during the following solution treatment.

Moreover, numerous studies have shown that second phase particles in alloy sheets could make a considerable difference to grain structures during the solution process [19]. The effects of second-phase particles on grain structures can be explained by Zener pinning pressure. With a given volume fraction $f$ of second phase particles with a mean radius $r$, Zener pinning pressure can be expressed by

$$
P_{\mathrm{Z}}=3 \gamma f / 4 r
$$

This equation demonstrates that the fine dispersoid second phase particles with a high density effectively hinder the grain boundary movement. The evolution of the second-phase particles in the $2195 \mathrm{Al}-\mathrm{Li}$ alloy is mainly reflected in the mutual transformation of small-sized particles $(1 \mu \mathrm{m})$ and large-sized particles ( $>5 \mu \mathrm{m}$; shown in Figure 9a). A visible reduction could be observed in the number of small-sized particles in the cold-rolled alloy annealed at $300{ }^{\circ} \mathrm{C}$ for $2 \mathrm{~h}$ due to dissolution or growth, which resulted in a decline of the density of particles and a weakening of the Zener pinning pressure. Therefore, the size of the grains grown and the average aspect ratio increased as well. However, in contrast to the samples annealed at $300{ }^{\circ} \mathrm{C}$, the number of large-sized particles and the average aspect ratio of the refined grains decreased, and the amount and density of small-sized particles increased in samples annealed at $400{ }^{\circ} \mathrm{C}$, ascribed to the large-sized particles starting to discompose.

\subsection{The Evolution of the Texture Structure}

The different texture types of the alloy possessed different change characteristics under different thermodynamic conditions. The volume fraction of the Goss $\{110\}<100>$ texture did not change much after annealing [20]. When the annealing temperature was relatively low, Copper $\{112\}<111>$ could be quickly transformed into $S\{123\}<634>$ and Brass $\{110\}<112>$, but only a small amount of $S\{123\}<634>$ and Brass $\{110\}<112>$ were converted to Cube $\{100\}<100>$. While the annealing temperature was relatively high, Copper $\{112\}<111>$ plentifully converted to Cube $\{100\}<100>$. The experimental results in this paper were confirmed to be consistent with the texture, as mentioned earlier theory. After annealing at $300{ }^{\circ} \mathrm{C}$, Copper $\{112\}<111>$ disappeared and the volume fractions of $S\{123\}<634>$ and Brass $\{110\}<112>$ increased, while the volume fraction of Cube $\{100\}<100>$ grew only slightly. At the annealing temperature on $400{ }^{\circ} \mathrm{C}$, the volume fractions of $S\{123\}<634>$ and Brass $\{110\}<112>$ decreased, and the volume fraction of Cube $\{100\}<100>$ increased.

Moreover, the recrystallization fractions were similar and all above $85 \%$ among the solutionized samples with different annealing treatments (shown in Table 5). The difference of the texture evolution between the samples can mostly be attributed to being various recrystallization modes mentioned above. It is well known that recrystallization modes include continuous recrystallization (i.e., in situ recrystallization), semi-continuous recrystallization, and discontinuous recrystallization [21]. Discontinuous recrystallization is usually completed by the migration of HABs with stored energy, which weakens the texture reinforcement linked to the volume fraction reduction of the Cube $\{100\}<100>$ 
texture. In this paper, after annealing at $300{ }^{\circ} \mathrm{C}$ and the subsequent solution treatment, the stored energy was partially released during the annealing process, resulting in an insufficient driving force to support discontinuous recrystallization in the subsequent solid solution treatment; therefore, only semi-continuous recrystallization could occur. Thus, the volume fraction of the deformation texture decreased, and the $S\{123\}<634>$ texture even disappeared, while the volume fraction of the Cube $\{100\}<100>$ texture increased in the annealed $\left(300^{\circ} \mathrm{C}\right)$ and solutionized samples. Increasing the annealing temperature to $400{ }^{\circ} \mathrm{C}$, a large amount of stored energy was released during the annealing process (as shown in Figure 11), part recovery and recrystallization occurred. Due to the lower temperature, the alloy only underwent semi-continuous recrystallization. According to Table 3, the $\beta$ fiber components decreased, and the cubic-oriented texture (Cube $\{100\}<100>$ texture and R-Cube $\{100\}<110>$ ) components increased significantly during the annealing process. Although stored energy was released in large quantities, the alloy could still be recrystallized, as the fine particles were extensively dissolved into the matrix after annealing treatment at $400{ }^{\circ} \mathrm{C}$, which decreased the obstacle of recrystallization. Therefore, the Brass $\{110\}<112>$ component was further reduced after the solution treatment, and the cubic orientation texture component also decreased compared to the samples annealed at $300^{\circ} \mathrm{C}$ and then solutionized.

\subsection{The Relationship between the Tensile Properties and the Microstructure Characteristics}

It is known that the strengthening mechanisms of $2195 \mathrm{Al}-\mathrm{Li}$ alloys include the strengthening of aging precipitates and grain structure [16]. As seen in Figure 11, the size and quantity of the $T_{1}$ phase in the aged samples annealed at $300{ }^{\circ} \mathrm{C}$ and $400{ }^{\circ} \mathrm{C}$ are almost the same. Therefore, strengthening the grain structures was considered the main factor of the studied alloy with different tensile properties under different annealing treatments. The strengthening of the grain structures was mainly due to the combined effects of grain refinement, a low aspect ratio, and modification of the texture. The increment of strength contributed by grain refinement usually abides by the Hall-Petch relationship:

$$
\sigma_{y}=\sigma_{0}+k d^{-1 / 2}
$$

where $\sigma_{y}$ refers to the alloy's yield strength; $d$ is the average diameter of the grains; $\sigma_{0}$ is rationalized as the internal resistant stress to deformation; and $k$ is the Hall-Petch slope, which reflects the resistance of the grain boundary to slip transfer. In this paper, there was no discernible difference between the aged alloy under different annealing temperatures by the calculation in Equation (4) and the study on the aspect ratio of the aged $\mathrm{Al}$ alloy linked to the tensile properties [22].

In the present study, the Taylor factor was emphatically calculated and used to assess the strength difference of the studied alloy with different texture components. The Schmid factors of conventional texture components in $\mathrm{Al}$ alloys $(\{111\}<110>$ slip system) are shown in Table 6.

Table 6. Schmid factor of textures corresponding to the $\{111\}<110>$ slip system in the Al alloy.

\begin{tabular}{|c|c|c|c|c|c|c|c|c|c|c|c|c|}
\hline Slip Plain & & 111 & & & $\begin{array}{l}-- \\
111\end{array}$ & & & $\begin{array}{r}-- \\
111\end{array}$ & & & $\begin{array}{l}-- \\
111\end{array}$ & \\
\hline Slip Direction & $\overline{-}$ & 101 & 011 & $\begin{array}{l}- \\
110\end{array}$ & $\begin{array}{l}-- \\
101\end{array}$ & $\begin{array}{r}-- \\
011\end{array}$ & 110 & 101 & 011 & $\begin{array}{l}-- \\
110\end{array}$ & $\begin{array}{l}- \\
101\end{array}$ & 011 \\
\hline Cube & 0.41 & 0.41 & 0 & 0.41 & 0.41 & 0 & 0.41 & 0.41 & 0 & 0.41 & 0.41 & 0 \\
\hline R-Cube & 0 & 0 & 0 & 0 & 0 & 0 & 0 & 0.41 & 0.41 & 0 & 0.41 & 0.41 \\
\hline Copper & 0 & 0.28 & 0.28 & 0 & 0 & 0 & 0.27 & 0 & 0.27 & 0.27 & 0.27 & 0 \\
\hline Brass & 0.41 & 0.14 & 0.27 & 0 & 0 & 0 & 0.14 & 0.41 & 0.27 & 0.27 & 0.28 & 0 \\
\hline Goss & 0.41 & 0.41 & 0 & 0.41 & 0.41 & 0 & 0.41 & 0.41 & 0 & 0.41 & 0.41 & 0 \\
\hline R-Goss & 0 & 0 & 0 & 0.41 & 0.41 & 0 & 0 & 0 & 0 & 0.41 & 0.41 & 0 \\
\hline S & 0.10 & 0.23 & 0.33 & 0.27 & 0.09 & 0.17 & 0.06 & 0.01 & 0.06 & 0.43 & 0.33 & 0.09 \\
\hline
\end{tabular}

In the single crystals, the Taylor factor, which indeed can be defined as the reciprocal to the Schmid factor. Brass $\{110\}<112>, S\{123\}<634>$, and Copper $\{112\}<111>$ texture components are of hard orientation with a lower Schmid factor, while Cube $\{100\}<100>$, R-Cube $\{100\}<110>$, and Goss $\{110\}<100>$ 
texture components are of soft orientation with a higher Schmid factor. On a specific slip system, the weighted Schmid factor of the alloy can be expressed by the following formula:

$$
m_{w}=\sum f_{i} \cdot m_{i}
$$

where $m_{w}$ refers to the weighted Schmid factor on the specific slip system; $f_{i}$ refers to the volume fraction of the specific texture component; and $m_{i}$ is the Schmid factor of the specific texture component on the specific slip system. According to the volume fractions of the various textures provided in Table 4 , and assuming that the uncalibrated textures are random textures $\left(\mathrm{M}_{\mathrm{R}}=3\right)$, the weighted Taylor factors on the five slip system can be calculated using the data from EBSD (listed in Table 7). Thus, the $M$ of solutionized samples with different annealing treatments prior to the solution treatment can be calculated (Table 7). The samples treated by annealing at $300^{\circ} \mathrm{C}$ and the subsequent solution treatment possess a higher average Taylor factor (2.94), while the samples treated by a low heating-up rate during the solution treatment possess a lower average Taylor factor (3.45).

Table 7. Weighted Schmid factors and average Schmid factors corresponding to the $\{111\}<110>$ slip system and of samples with different annealing treatments prior to solution.

\begin{tabular}{|c|c|c|c|c|c|c|c|c|c|c|c|c|c|}
\hline Slip Plain & & 111 & & & $\overline{111}$ & & & $\overline{111}$ & & & $\overline{111}$ & & \\
\hline Slip Direction & $\overline{110}$ & 101 & 011 & $\overline{110}$ & $\overline{101}$ & $\begin{array}{r}-- \\
011\end{array}$ & 110 & 101 & $\begin{array}{r}-\overline{1} \\
011\end{array}$ & $\begin{array}{l}-- \\
110\end{array}$ & $\begin{array}{l}\overline{-} \\
101\end{array}$ & 011 & $\mathbf{M}$ \\
\hline direct solution & 0.31 & 0.30 & 0.31 & 0.29 & 0.27 & 0.24 & 0.28 & 0.30 & 0.27 & 0.34 & 0.33 & 0.24 & 3.13 \\
\hline $300{ }^{\circ} \mathrm{C}$ & 0.35 & 0.32 & 0.27 & 0.30 & 0.30 & 0.24 & 0.32 & 0.35 & 0.27 & 0.34 & 0.34 & 0.24 & 2.94 \\
\hline $400^{\circ} \mathrm{C}$ & 0.31 & 0.31 & 0.30 & 0.30 & 0.27 & 0.25 & 0.28 & 0.29 & 0.26 & 0.35 & 0.33 & 0.24 & 3.13 \\
\hline low heating-up rate & 0.27 & 0.26 & 0.27 & 0.18 & 0.15 & 0.12 & 0.23 & 0.25 & 0.21 & 0.33 & 0.32 & 0.10 & 3.45 \\
\hline
\end{tabular}

Besides, many authors have summed many strengthening terms to clarify the relationship between each influencing factor and strength [23]. As mentioned earlier, the Hall-Petch relationship can well clarify the relationship between grain size and alloy strength. Additionally, for other factors, the strengthening terms can be summed by the following relationship:

$$
\sigma_{y}=\sigma_{g b}+\mathrm{M}\left(\sigma_{b}+\Delta \sigma_{s s}+\Delta \sigma_{\rho}+\Delta \sigma_{p}\right)
$$

where $\sigma_{y}$ refers to the yield strength of the alloy; $\sigma_{b}$ refers to the constant base shear strength; $\Delta \sigma_{s s}$, $\Delta \sigma_{\rho}$, and $\Delta \sigma_{p}$ refers to the increment in strength due to solid solution hardening, strain hardening, and precipitation hardening, respectively; and M refers to the Taylor factor [23]. In the present study, the value of $\sigma_{\mathrm{gb}}$ among the aging alloy under a different preliminary heat treatment prior to the solution heat treatment was similar, which was ascertained by the calculation on the Equation (4). In addition, all of the samples possessed the same composition, pre-deformation, and similar precipitation. The value of $\sigma_{b}, \Delta \sigma_{s s}, \Delta \sigma_{\rho}$, and $\Delta \sigma_{p}$ of all of the samples with different annealing treatments prior to the solution can be assumed the same. Therefore, the value of $\sigma_{y}$ was determined by the value of the average calculated Taylor factor M. In the strength values of the aging alloy listed in Table 4, the value of the sample without annealing and under annealing at $400{ }^{\circ} \mathrm{C}$ was similar ( $587 \mathrm{MPa}$ and $\left.585 \mathrm{MPa}\right)$, with a corresponding similar value of $\mathrm{M}$ on 3.13 (shown in Table 7). The strength of the aging sample under a low heating-up rate (598 MPa) was higher than that without annealing (587 MPa), which was in accord with the more considerable value of $M$ under a low heating-up rate (3.45) than that without annealing (3.13). Besides, the decrease of the aging alloy under annealing at $300{ }^{\circ} \mathrm{C}$ comparing to that without annealing kept in line with the lower value of $\mathrm{M}$ (2.94) under annealing to without annealing (3.13). In summary, the calculated values of $M$ in the present study were well accorded with the aged alloy's strength difference characteristic under different preliminary heat treatment schedules. The average Taylor factor calculation is also a meaningful way to explain the cause of the strength differences of the aged alloys with different grain structure characteristics. 


\section{Conclusions}

(1) The preliminary annealing heat treatments prior to the solution treatment have a significant effect on the structure of grains of the $2195 \mathrm{Al}-\mathrm{Li}$ alloy. After annealing at $300{ }^{\circ} \mathrm{C}$ prior to solution treatment, the fraction of equiaxed grains decreased dramatically, and the elongated grains coarsened in solutionized samples. In contrast, the grain refined in the samples annealed at $400{ }^{\circ} \mathrm{C}$ and then solutionized.

(2) Due to the similar precipitation characteristics of the aging alloy under different preliminary annealing heat treatments prior to the solution treatment, the different mechanical properties of the aging alloy were related to the grains' structure.

(3) The decrease of the strength along the longitudinal and transverse direction and the heterogeneity of the aging alloy under the annealing at $300{ }^{\circ} \mathrm{C}$ prior to the solution treatment was derived from the decrease of the fraction of the deformation texture components and the increase of the volume of Cube $\{100\}<100>$. While the decrease of the strength along the transverse direction and the increase of the heterogeneity of the aging alloy under the annealing at $400{ }^{\circ} \mathrm{C}$ prior to the solution treatment were attributed to the increase of the fraction of the deformation texture components and the decrease of the volume of Cube $\{100\}<100>$.

(4) Compared to the directly solutionized samples, the grain structure was dominated by the texture components in aging samples treated at a low heating-up rate in the solution process, which possessed a higher strength in the longitudinal direction.

Author Contributions: Data curation, Y.-L.M.; Project administration, J.-F.L.; Supervision, J.-F.L.; Writing-original draft, T.-L.L.; Writing-review \& editing, D.-Y.L. All authors have read and agreed to the published version of the manuscript.

Funding: This work was supported by Postdoctoral Research Foundation of China and the National Foundation of China (No. TDZX-17-005-1).

Conflicts of Interest: The authors declare no conflict of interest.

\section{References}

1. Nayan, N.; Murty, S.V.S.N.; Jha, A.K.; Pant, B.; Sharma, S.C.; George, K.M.; Sastry, G.V.S. Processing and characterization of $\mathrm{Al}-\mathrm{Cu}-\mathrm{Li}$ alloy AA2195 undergoing scale up production through the vacuum induction melting technique. Mater. Sci. Eng. A 2013, 576, 21-28. [CrossRef]

2. Li, J.F.; Liu, P.L.; Chen, Y.L.; Zhang, X.H.; Zheng, Z.Q. Microstructure and mechanical properties of Mg, Ag and Zn multi-microalloyed Al-(3.2-3.8)Cu-(1.0-1.4)Li alloys. Trans. Nonferrous Met. Soc. Chin. 2015, 25, 2103-2112. [CrossRef]

3. Dorin, T.; Deschamps, A.; Geuser, F.D.; Robaut, F. Impact of grain microstructure on the heterogeneity of precipitation strengthening in an Al-Li-Cu alloy. Mater. Sci. Eng. A 2015, 627, 51-55. [CrossRef]

4. Zhang, P.; Ye, L.Y.; Zhang, X.M.; Gu, G.; Jiang, H.C.; Wu, Y.L. Grain structure and microtexture evolution during superplastic deformation of 5A90 Al-Li alloy. Trans. Nonferrous Met. Soc. Chin. 2014, 24, 2088-2093. [CrossRef]

5. Li, J.F.; Ye, Z.H.; Liu, D.Y.; Chen, Y.L.; Zhang, X.H.; Xu, X.Z.; Zheng, Z.Q. Influence of Pre-deformation on Aging Precipitation Behavior of Three Al-Cu-Li Alloys. Acta Metall. Sin. 2017, 30, 133-145. [CrossRef]

6. Tsivoulas, D.; Prangnell, P.B. The effect of Mn and $\mathrm{Zr}$ dispersoid-forming additions on recrystallization resistance in Al-Cu-Li AA2198 sheet. Acta Mater. 2014, 77, 1-16. [CrossRef]

7. Fan, X.B.; He, Z.B.; Lin, P.; Yuan, S.J. Microstructure, texture and hardness of Al-Cu-Li alloy sheet during hot gas forming with integrated heat treatment. Mater. Des. 2016, 94, 449-456. [CrossRef]

8. Ma, Y.L.; Li, J.F.; Sang, F.J.; Li, H.Y.; Zheng, Z.Q.; Huang, C. Grain structure and tensile property of Al-Li alloy sheet caused by different cold rolling reduction. Trans. Nonferrous Met. Soc. Chin. 2019, 29, 1569-1582. [CrossRef]

9. Wang, Q.; Yang, P.; Zhang, B.R.; Fan, H.; Xu, X.X.; Li, W.B.; Fan, X.L.; Wang, J.F.; Ding, H.M. Microstructure and texture evolution of cold rolled $1070 \mathrm{Al}$ alloy during the subsequent annealing treatment. Results Phys. 2019, 13, 102178. [CrossRef] 
10. Suresh, M.; Sharma, A.; More, A.M.; Nayan, N.; Suwas, S. Effect of Scandium addition on evolution of microstructure, texture and mechanical properties of thermo-mechanically processed Al-Li alloy AA2195. J. Alloys Compd. 2018, 740, 364-374. [CrossRef]

11. Xiao, H.; Jiang, S.S.; Zhang, K.F.; Jia, Y.; Shi, C.C.; Lu, Z.; Jiang, J.F. Optimizing the microstructure and mechanical properties of a cold rolled Al-Mg-Li alloy via electropulsing assisted recrystallization annealing and aging. J. Alloys Compd. 2020, 814,1-14. [CrossRef]

12. Vasudevan, A.K.; Przystupa, M.A.; Fricke, W.G. Effect of composition on crystallographic texture of hot-rolled Al-Li binary alloys. Mater. Sci. Eng. A 1995, 196, 1-8. [CrossRef]

13. Roy, R.K.; Kar, S.; Das, S. Evolution of microstructure and mechanical properties during annealing of cold-rolled AA8011 alloy. J. Alloys Compd. 2009, 468, 122-129. [CrossRef]

14. Wang, X.F.; Guo, M.X.; Chapuis, A.; Luo, J.R.; Zhang, J.S.; Zhuang, L.Z. The dependence of final microstructure, texture evolution and mechanical properties of Al-Mg-Si-Cu alloy sheets on the intermediate annealing. Mater. Sci. Eng. A 2015, 633, 46-58. [CrossRef]

15. Huo, M.S.; Zhao, J.W.; Xie, H.B.; Jia, F.H.; Li, S.L.; Zhang, H.M.; Jiang, Z.Y. Effects of micro flexible rolling and annealing on microstructure, microhardness and texture of aluminum alloy. Mater. Charact. 2019, 148, 142-155. [CrossRef]

16. Liu, D.Y.; Sang, F.J.; Li, J.F.; Birbilis, N.; Wang, Z.X.; Ma, Y.L.; Zhang, R.F. The role of grain structure characteristics on the localised corrosion feature in the $1445 \mathrm{Al}-\mathrm{Cu}-\mathrm{Li}$ alloy. Mater. Charact. 2019, 158, 109981. [CrossRef]

17. Dobatkin, S.V.; Bastarache, E.N.; Sakai, G.; Fujita, T.; Horita, Z.; Langdon, T.G. Grain refinement and superplastic flow in an aluminum alloy processed by high-pressure torsion. Mater. Sci. Eng. A 2005, 408, 141-146. [CrossRef]

18. Bennett, T.A.; Petrov, R.H.; Kestens, L.A.I. Effect of particles on texture banding in an aluminum alloy. Scr. Mater. 2010, 62, 78-81. [CrossRef]

19. Shuai, L.F.; Huang, T.L.; Wu, G.L.; Huang, X.; Mishin, O.V. Development of Goss texture in Al-0.3\%Cu annealed after heavy rolling. J. Alloys Compd. 2018, 749, 399-405. [CrossRef]

20. Chuang, Y.H.; Cho, K.K.; Han, J.H.; Shin, M.C. Effect of grain shape and texture on the earings in an Al-Li alloy. Scripta Mater. 2000, 43, 759-764. [CrossRef]

21. Shanmugasundaram, T.; Heilmaier, M.; Murty, B.S.; Sarma, V.S. On the Hall-Petch relationship in a nanostructured Al-Cu alloy. Mater. Sci. Eng. A 2010, 527, 7821-7825. [CrossRef]

22. Myhr, O.R.; Grong, O.; Andersen, S.J. Modellding of the age hardening behavior of Al-Mg-Si alloys. Acta Mater. 2001, 49, 65-75. [CrossRef]

23. Bardel, D.; Perez, M.; Nelias, D.; Deschamps, A.; Hutchinson, C.R.; Maisonnette, D.; Chaise, T.; Garnier, J.; Bourlier, F. Coupled precipitation and yield strength modeling for non-isothermal treatments of a 6061 aluminum alloy. Acta Mater. 2014, 62, 129-140. [CrossRef] 